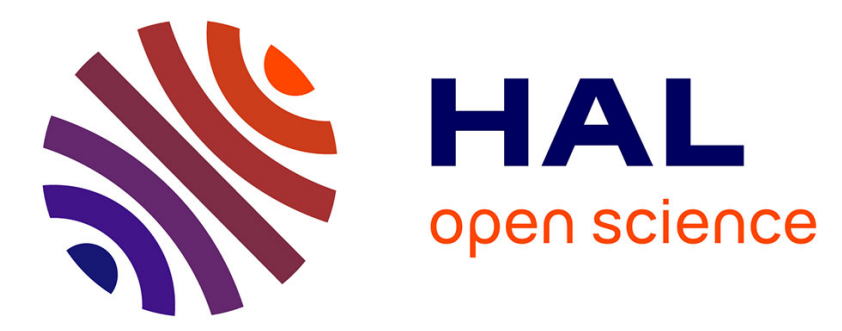

\title{
From Knowledge to Sign Management: A Co-design Methodology for Biodiversity and Music Enhancement
}

Noël Conruyt, Véronique Sébastien, Olivier Sébastien, Didier Sébastien, David

Grosser

\section{- To cite this version:}

Noël Conruyt, Véronique Sébastien, Olivier Sébastien, Didier Sébastien, David Grosser. From Knowledge to Sign Management: A Co-design Methodology for Biodiversity and Music Enhancement. 3rd IFIP International Workshop on Artificial Intelligence for Knowledge Management (AI4KM), Jul 2015, Buenos Aires, Argentina. pp.80-105, 10.1007/978-3-319-55970-4_6 . hal-01626986

\section{HAL Id: hal-01626986 https://hal.inria.fr/hal-01626986}

Submitted on 31 Oct 2017

HAL is a multi-disciplinary open access archive for the deposit and dissemination of scientific research documents, whether they are published or not. The documents may come from teaching and research institutions in France or abroad, or from public or private research centers.
L'archive ouverte pluridisciplinaire HAL, est destinée au dépôt et à la diffusion de documents scientifiques de niveau recherche, publiés ou non, émanant des établissements d'enseignement et de recherche français ou étrangers, des laboratoires publics ou privés.

\section{(c)(1)}

Distributed under a Creative Commons Attribution| 4.0 International License 


\title{
From Knowledge to Sign Management: a Co-design methodology for Biodiversity and Music enhancement
}

\author{
Noël Conruyt, Véronique Sébastien, Olivier Sébastien, \\ Didier Sébastien and David Grosser \\ LIM, EA 25-25, University of Reunion Island, 97490, Sainte-Clotilde, France \\ \{noel.conruyt, veronique.sebastien, olivier.sebastien, \\ didier.sebastien, david.grosser\}@univ-reunion.fr
}

\begin{abstract}
When using Artificial Intelligence techniques for Knowledge management in decision support systems, the enhancement of knowledge should be based both on artificial machine learning methods and a natural human learning approach. Indeed, knowledge representation with ontologies and CaseBased Reasoning (CBR) is not enough for gaining qualitative results in decision support systems. We need to manage know-how, i.e. living knowledge. For example, enhancing biodiversity and music means teaching and learning the effectiveness of individual and living interpretations (how to observe a natural specimen, how to play a music sheet). The quality of descriptions is thus very important to correctly classify or identify marine or terrestrial organisms, or learn adequately an instrument such as the guitar or the piano. This paper introduces Sign management to tackle this qualitative learning problem in AI. Then, a Codesign methodology and a cooking method on a Creativity Platform are proposed: when dealing with such complex domains, we need to focus on the signification of knowledge construction that operates in co-designing an eservice that should be useful for reaching a more robust knowledge base. Our finding is that due to different interpretations of domain objects from subjects (persons), we need sign bases to move from written expert knowledge transmission to multimedia know-how sharing in the community for getting better results.
\end{abstract}

Keywords: Knowledge management, Sign management, Co-design methodology, E-service, Creativity Platform, Biodiversity, Music.

\section{$1 \quad$ Introduction}

Fifteen years ago at University of Reunion Island, some researchers of the mathematics and computer science team (LIM) decided to apply Knowledge Engineering and Human-Computer Interaction to the enhancement of biodiversity and music for educational purpose. Starting from a Knowledge management methodology in Systematics, a teaching tool called IKBS (Iterative Knowledge Base System) was codesigned between computer scientists and biological experts. The knowledge base was 
used for modeling and describing their collection of plant and coral specimens with written and structured knowledge. The objective was to help them classify species and transmit their knowledge to other biologists to allow the latters to identify new specimens.

But this top-down teaching approach of describing biological objects with IKBS appeared to be a real bottleneck in the identification help process. The problem of interpretation of specimen characters made by specialists emerges when the knowledge base is put in the hands of other biologists: the latters are not able to observe and describe biological objects, characters and values with the same know-how and accuracy as experts when they are left alone, thus leading to wrong identifications. A new bottom-up learning strategy was then required based on sharing observation knowhow rather than transmitting knowledge.

The interpretation problem is identical when dealing with instrumental music. To learn an instrument such as the guitar or the piano, a course with a professor is the best way to perform pieces that are described on scores with musical objects. The teacher shows how he interprets the notes in front of the student. But after the course, the learner is left alone with the music sheet and has to remember all the fingerings and gesture details.

So, we decided to co-design a new type of e-service with teachers and learners called a sign base, dedicated to the formers, in order to show their know-how with multimedia content, and to the latters to reproduce the right fingering, movement, sound and play correctly a piece of music at home, and ask questions to the professor. This "teaching and learning" tool is needed to acquire and share gesture know-how.

\section{From Knowledge to Sign management}

Knowledge management is not sufficient for enhancing our biodiversity and music domains. The association of terms must be clarified because knowledge is difficult to manage on its own. Only information ('informatio' = to give a form) that is transmitted between subjects on objects can be captured and managed by computer scientists in information systems. Data are raw content elements (values of attributes) of information measured on objects. Knowledge is registered either between 1) the ears of somebody, i.e. in their head or 2) in books.

In the first case, it is the "subjective" sense or meaning, i.e. the sign-ification (construction of signs) of an object, made of tacit knowledge by a subject. This practical knowledge is the result of a long experience of some experts that have experimented a lot of cases in the fields, and formed their know-how by compiling them continuously in their mind. We consider that this living knowledge, which is made of performances, can be managed by acquiring multimedia contents in the form of annotations.

In the second case, it is the "objective" written result, the formalized representation or know-what that can be found in documents or books such as musical scores (notations) or species taxonomies (monographs). This explicit form made of descriptions is dead knowledge, but it can be updated if it is structured and formatted adequately. 
In general, computer scientists manage the second type of knowledge by using Semantic Web in the linguistic semiotics tradition [1] rather than the first type that is more pragmatic [2]. Hence, Knowledge management is mostly viewed as representing objects with description logics and transmitting formal knowledge in knowledge bases as a result of classifying descriptions in a teaching linear mode.

For our part, we consider that both types of knowledge are central to manage for obtaining qualitative teaching and learning results. We advocate the importance of design (sign revelation) and signification (sign construction) for building e-services that really matter for end-users. In this user-centered approach, both artificial and natural, Knowledge management is embedded in Sign management (Fig. 1).

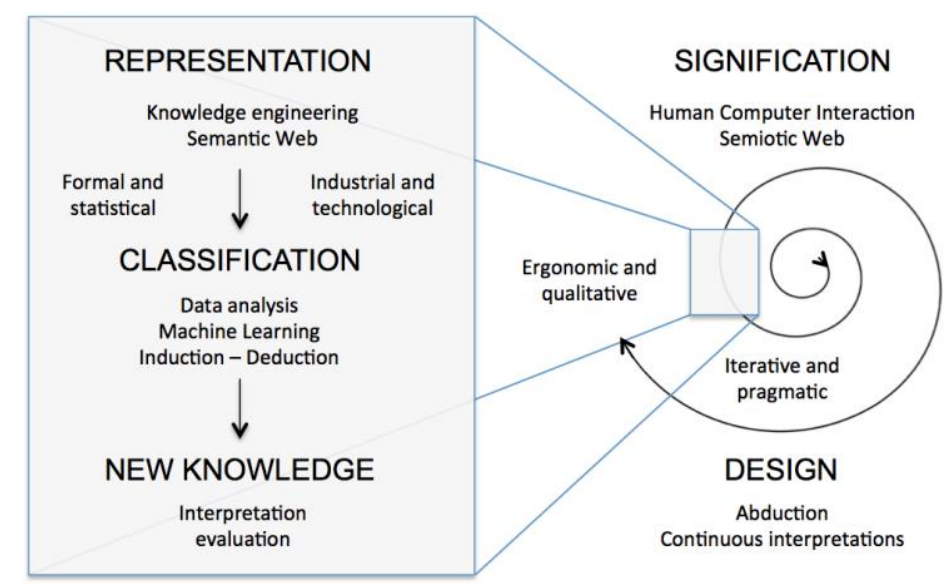

Fig. 1. Knowledge (left) and Sign management (right)

Consequently, the notion of Sign is more general than Knowledge for our purpose in music and biology. A Sign (Fig. 2 on the left) is represented by a tetrahedron with Data, Information, Knowledge and Interpreter at its corners. It is the interpretation of an Object by a Subject at a given time and place, which considers its content (data, fact, event), its form (information), and its sense or meaning (knowledge). What is exchanged on a support between Subjects is called Information and this digitized codification can be managed.

The Signification or semiosis (Fig. 2 on the right) is the continuous process of using Signs in human thinking for acquiring Objects interpreted by Subjects (see arrows in Fig. 2). The Subject operates on Signs in two phases: reflection and action. These phases are inter-linked in an iterative cycle with a helical spiral shape including six moments: 1) to desire, 2) to do, 3) to know, 4) to interpret, 5) to know-how for oneself, 6) to communicate to others. The semiosis spiral is included in the tetrahedron of the Sign. The edges represent the three fundamental characteristics of a Subject 's interpretation on an Object, i.e. volition, action and cognition.

Sign management is based on the signification process (construction of signs) and comes from the pragmatic learning theories, i.e. umwelt [3], activity [4], and biosemiotics [5]. It is a human machine interaction process that follows the living 
beings' paradigm: signification or semiosis is to give sense to our perceptions, actions, and understanding of situations.
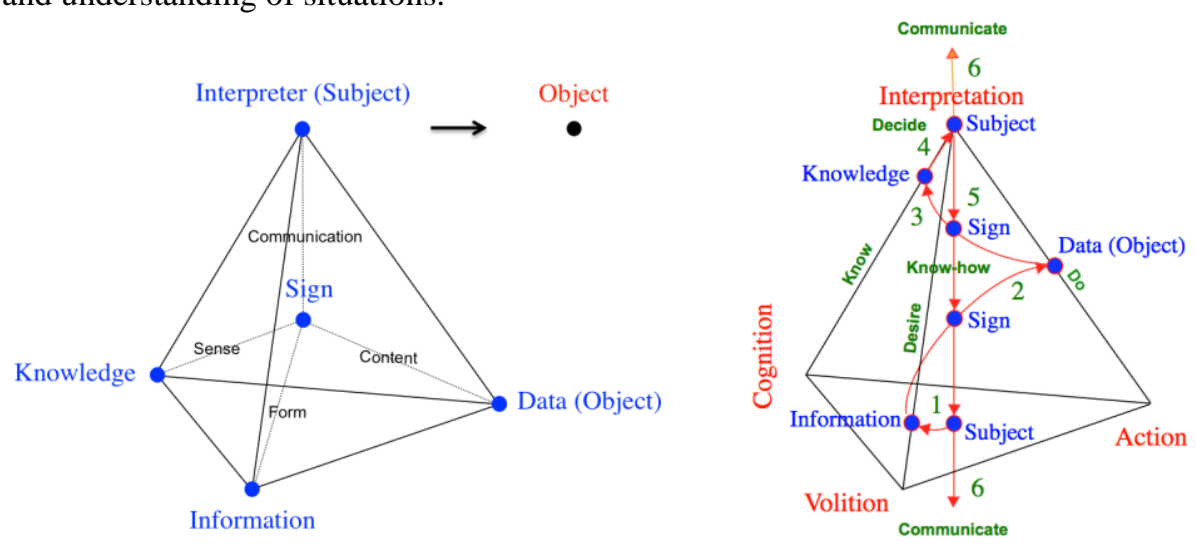

Fig. 2. The Sign tetrahedron representation and the signification process

Therefore, it is an ergonomic and qualitative approach that is mostly constructivist, reflexive and iterative, like in the natural ecosystems where living organisms use mostly the abduction principle (make hypotheses) to innovate continuously for surviving in the environment. Sign management is then more human-centred than Knowledge management: it places inductive and deductive methods and technologies at the service of human development and not the contrary. In this context, Design and Signification are the core elements of Semiotic Web for making e-services [6].

As such, ISBS (Iterative Sign Base System) will be a dynamic and iterative process between ontologies (definitions), instances (descriptions), generalizations (classifications) and performances (interpretations) that are shown in a sign base for them to be more robust in complex domains such as Biodiversity and Music enhancement [7].

\section{$3 \quad$ Biodiversity and music enhancement}

Starting from these two knowledge transmission problems in biology and music, a Codesign methodology based on Sign management is proposed in this paper. We will argue that the representation of objects for machine learning is necessary but not sufficient for capturing and transmitting knowledge: the ontology modeling for cases description is only the engineering and written business object activity of the process of Knowledge management, made by computer scientists and domain specialists. In fact, we need also the other Human Computer Interaction side for getting the signification of objects, called the design and usage object activity. It is dedicated to other end-users who are not experts. Indeed, the specialists must teach each biological or musical object with multimedia means (illustrations, 3D simulations, videos) in order that the users can reproduce them visually or kinesthetically ("show me your knowhow"). Learners who incorporate the meaning of objects by practicing it (embodiment) 
better understand them for solving their visual appreciation (right values of attributes in Systematics) or gestural interpretation (right melodies and rhythms in harmony for playing Music).

\section{Teaching and learning approach for Systematics}

We have experienced the building of knowledge bases in biology for 30 years since the first expert system in agriculture in France for identifying tomato diseases, called TOM [8]. The knowledge acquisition bottleneck of gaining expert rules led us to adopt a machine learning and CBR approach in European projects $[9,10]$. We applied these symbolic and numeric induction techniques in the domains of marine Systematics for sponges and corals classification and identification purposes [11].

The IKBS Knowledge Base Management System that we designed for specialists could be used directly by them for defining characters (objects, attributes, values) and structure a descriptive model with descriptive logics, i.e. relational dependencies (parts, viewpoints, specializations), then describe cases in a questionnaire based on this ontology [12]. Then, descriptions were used to build a decision tree with ID3 information gain for identification of new observations, or dissimilarity measures (knearest neighbors) techniques to classify or compare supervised cases or unsupervised observations (Fig. 3).

The experimentation and validation process of classifications and identifications with biologists showed that the robustness of our knowledge bases (around 70\% of good results) relies on 1) iterating on the definition of the descriptive model to better explain the signification of characters to end-users, 2) storing different subject descriptions of the same specimen in the case base (inter-observer variation), and 3) multiplying the number of specimen descriptions in the case-base to cover intra-specific variation.

The experts, aware of the importance of transmitting their knowledge to other biologists, postulates more precise and relevant characters that may be easier to observe and/or offer less ambiguous values (easier to interpret) in their descriptive model. For example, they will refine it based on mutually exclusive values, monosemic attributes, position of objects' attributes, glossary of terms, warning messages and observation help, enhanced illustrations and animations [13].

The biological Knowledge management that we have experienced with IKBS is mostly centered on the expert teaching of domain objects toward biological end-users. But building knowledge bases with AI techniques relies not only on explicit expert know-how. This living knowledge should be shared between practitioners of a community to be questioned and find a consensus. The fact is that we have always the specimen on the table, and every describer can come back to review it, better observe the characters and evaluate them.

Lastly, managing biodiversity is a complex multi-dimensional endeavor that uses specimen collections. We are at the beginning of digitalizing them in museums. Each specimen should have a morphological description of objects (components) that is conform to a common descriptive model of the parent taxa (Species, Genus, Family, etc.) and should be stored in knowledge bases of virtual museums for future retrieval. 


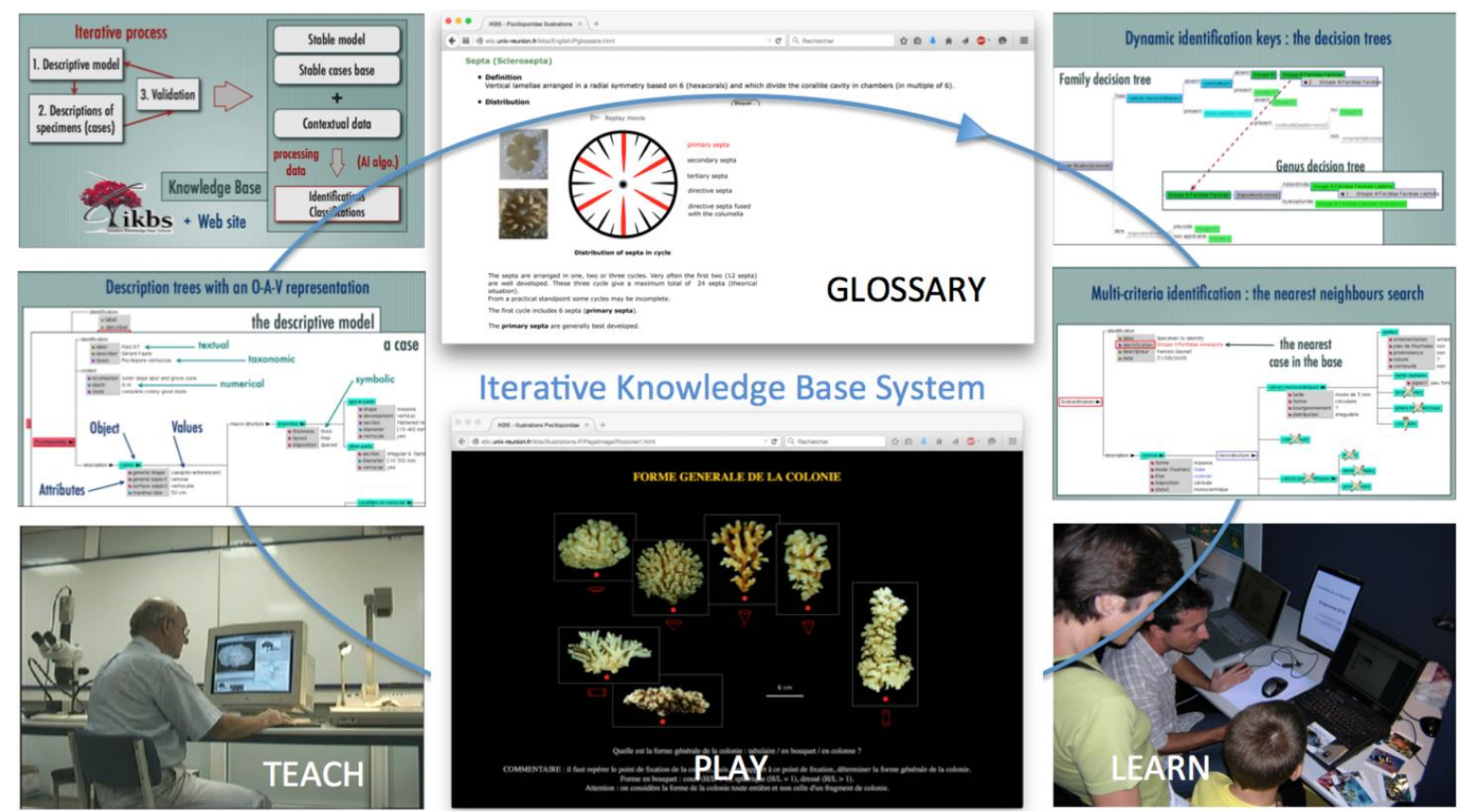

Fig. 3. The teaching and learning approach of Knowledge management with IKBS 


\section{Teaching and learning approach for playing an instrument}

The building of knowledge bases in instrumental music began ten years ago with an idea: how to capture the know-how of artists and professors, i.e. their finger movements that reproduce the right and lovely sound of a music piece? Because when we are left alone at home with our instrument after the course with the professor, we are not able to remember all the fingerings that are written on the scores and how to play them correctly.
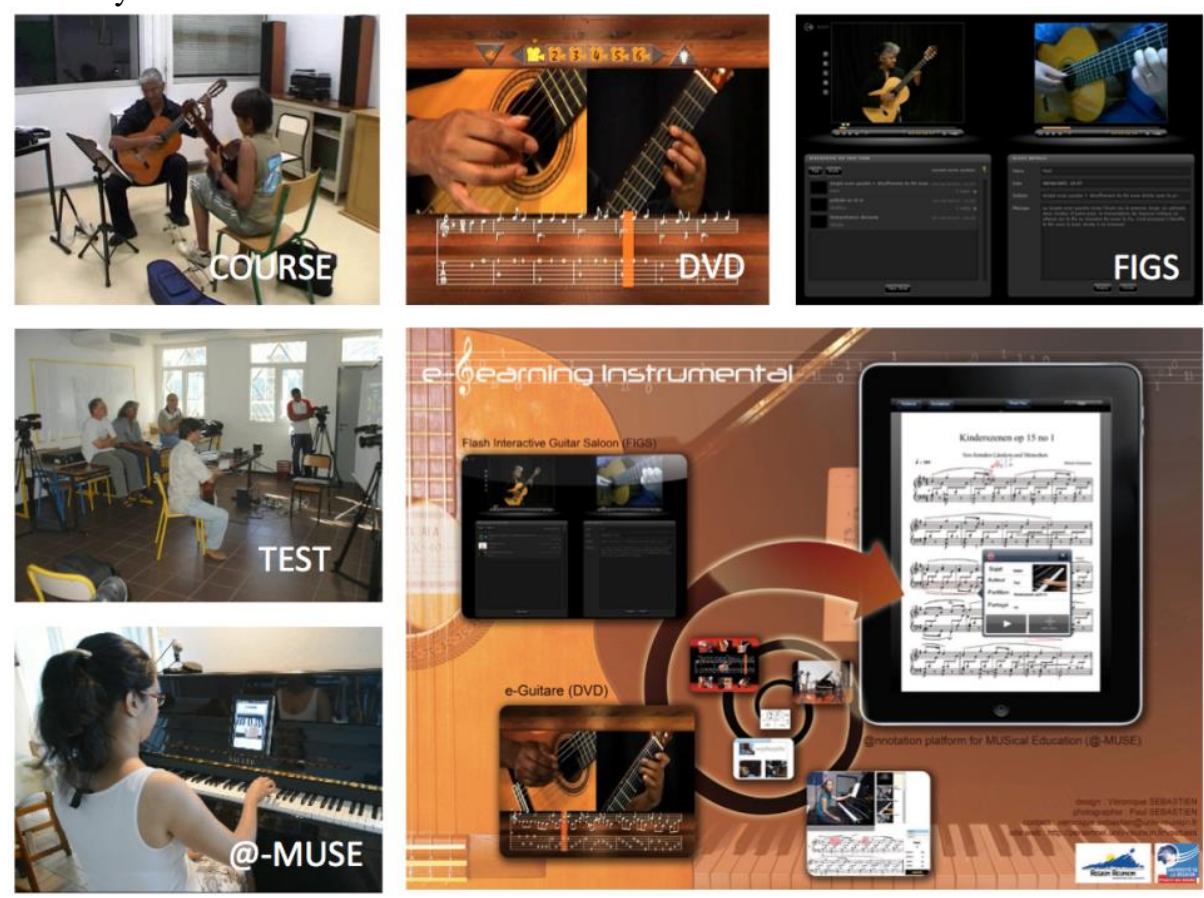

Fig. 4. The teaching and learning approach of Sign management with tools

So we started to answer this question with an instrumental e-learning project on the guitar [14] to collect master pieces in DVDs, showing a musical karaoke that binds the score with six multi-angle videos (Fig. 4 above).

The transmission of knowledge through this offline solution is a teaching (topdown) approach. The designed prototype was experimented twice on a Co-design Platform (see below) with learners and professors. The capability to learn a piece of music by reproducing the same gesture of the piece was emphasized by learners: for instance, they could choose to focus on the right hand and loop in slow motion on a part of the score. The DVDs gave good learning results but learners would have appreciated more feedbacks (pedagogical advices) from professors. So, we designed another glosses system on the Web called FIGS (Flash Interactive Guitar Saloon). It allows learners to ask questions to teachers from their webcam at home. Videos are indexed to a part of the track of the piece. The professor shows his technical solution or 
performance by filming himself also at home after receiving an email. He doesn't need to be connected synchronously to the system but the dialog is bidirectional.

This instrumental online e-learning solution was the start for another complementary project in 2009 on the piano [15]. The idea was to allow performers to show their fingerings by the means of using annotations of scores on tablets. @-MUSE (@nnotation platform for MUSical Education) aims at constituting a Musical Sign Base (MSB) rather than a Knowledge Base. Indeed, the focus for playing an instrument is more on the learning (bottom-up) of practices by sharing know-how with video annotations. @-MUSE stores MusicXML scores as written knowledge (notation) and allows each player to index his interpretation (know-how) as a filmed annotation in any part of the score (Fig. 4 right). Moreover, the annotations can be shared in the frame of a community of musicians playing the same sheet of music, and reused for similar pieces.

The learning method on tablets has not yet been tested in the field of music schools because of a lack of means to finalize the prototype. The coupling of @-MUSE with a musical editor such as MuseScore [16] was under consideration but this endeavor needs a partnership with a private company that has not been realized. We are here at the frontier of research and innovation, with a new ecosystem to build between our computer science laboratory, a private company and the targeted public (musicians). It is the reason why we try to promote the concept of Living Labs at our university to open to the outside world with a Co-design methodology.

\section{A Co-design methodology for making e-services}

In both application domains of biodiversity and music enhancement explained above, we had to deal with the problem of modeling qualitative interpretations of natural and cultural objects, observed by different types of agents (expert, novice), i.e. how to observe specimens for right identification of species names, and how to play nicely a piece of music with a musical instrument.

The question is how ICT can help to achieve these aims, i.e. build e-services that facilitate the teaching and learning of such qualitative know-how. For this purpose, we emphasize 1) the use of design to reveal the signs of the ICT product or e-service to conceive, 2) a living lab for enhancing ideas and making projects, 3) a Co-design platform for processing collaborative design and experimenting mock-ups and prototypes and 4) an evaluation based on focus groups and questionnaires for assessing the results in terms of quality of e-services.

\section{Designing for revealing signs}

When designing a computerized solution for know-how management, we must concretize the signs that are the intention or purpose of an e-service that is useful for some individuals. The term design comes from the Latin word designo (with "de" meaning to reveal) and was popularized at the Renaissance period in Italy (disegno) [17]. Thus, the intention (sign) is at the beginning of the process of creativity. These 
signs characterize something that is desired in human mind. They are the ingredients of an idea that can evolve into a concept, take shape in a mock-up, and then become tested in prototypes before realizing an e-service.

For example, the desire of a beginner in classical guitar would be to play the famous piece "Forbidden Games" in the same way as a performer whom he admires.

In the instrumental e-learning concept, i.e. e-guitare, the request was to reproduce the performance of a piece, by watching a teacher's hands. The vision is as follows: Imagine, your guitar nicely sitting on your knee, you are listening to the guitar piece "Forbidden Games" and at the same time you are watching your guitar teacher's hands on your screen. Close-ups, slow motions, rewinding, and loops: many options are offered so that you can play at the same time as the teacher. To help you, the inset score lights up each note as it is played. All this is on high definition video, on full screen with real stereo sound! In addition, the teacher's advice, in visual and oral form, accompanies the notes and bars being played (see the DVD of Fig. 4). The problem is therefore to define the steps by which this vision may become real with products (DVDs) or e-services (FIGS, @-MUSE).

But as elsewhere, to fructify ideas, people who are involved in the de-sign process must find an ecosystem that helps them to concretize their motivation.

\section{Enhancing ideas in a living Lab}

As explained above for making e-services, the first step is to generate ideas and show concepts of e-services. This ideation process should be attractive for motivating some researchers to drive innovative projects.

Living Labs (LLs) are those desirable innovation ecosystems (breeding grounds) for enhancing experimental research, find user-centered-design solutions and go to the market, i.e. make ideas become alive (emergence of ideas) towards useful (usage value) and profitable (economic value) products and services.

Curley and Salmelin [18] consider LLs as a significant example of the open innovation 2.0 ecosystem where users are engaged in co-creating value together with all project stakeholders. In contrast, test-beds, usually technology driven, involve users as observed subjects. A LL combines the User eXperience (UX) quality in co-creating, exploring and experimenting with users a product or service that has the capacity to capture previous design experiences [19].

For enhancing ideas, a LL brings together public, private, companies, associations, individual actors, whose goal is to design, develop and test full-scale services, tools or new uses [20]. One aim is for example to out research labs and to move it down in the life of every day, often with a strategic view of the potential uses of these contents and technologies. All this happens in cooperation between local authorities, companies, research laboratories, as well as potential users through platforms offering the possibility to design innovative and analytical uses.

In Reunion Island, we found that in the innovation chain leading from idea to product/services used and marketable, there is a need to implement an important step, one that leads from idea to prototype, through the co-design of the concept, layout, and various drivers to experiment. The missing link that we have identified at University of 
Reunion Island is the insemination of ideas to prototype before incubation in an innovative company. Indeed, the production and use values of the designed solutions must be acknowledged before reaching their economic values, i.e. whether the prototypes are efficiently built by producers and editors, and if they will be adopted by their targeted users/citizens/consumers.

In this business and usage context, our LL aims to host content producers, i.e. researchers, teachers, entrepreneurs and users to help them develop projects of cocreation of e-services in the various fields that characterize the specificity and the advantages of the territory for its sustainable development.

We want to accompany the process of ideation-design of talented persons (lead users) who wish to develop tools to serve a definite purpose in an area. For example, the idea in biodiversity management is to "better understand our environment to better preserve it because one only protects what one knows and appreciates". The idea in instrumental music is to bring the teacher at home in proposing to mimic the gesture that produces good sound, to slow down, to loop over a passage, or to put oneself in the eyes of the teacher to have his own subjective view.

So, we conceived our LL in education as a real and virtual laboratory for Teaching and Learning Sciences and Arts by Playing [21]. Indeed, edutainment is one of the pillars of the future Web [22]. With game-based learning, we consider that we can play seriously to better know our natural and cultural environment and then better protect it.

As an example of edutainment in biodiversity protection, Fig. 5 shows a virtual ballad in the lagoon where learners can click on fishes to try to identify their name with a questionnaire and then access to information. This e-learning project proposed a $3 \mathrm{D}$ prototype for pedagogical access to information in a reef fishes' database. It involved an association [23] for enhancing marine contents to a large public. This virtual ballad is a $3 \mathrm{D}$ layer built upon the IKBS platform for accessing questions to identify fishes' names.

For edutainment in music, Fig. 6 shows our real and virtual laboratory in instrumental e-learning for playing the e-guitare DVDs with the iteration process between the production side of the DVD (Teaching) and its usage side (Learning). It makes use of the e-campus project for accessing music pieces through a metaverse and a Massive Multiplayer Online Role Playing Game [24, 25]. Our University of Reunion island Living Lab in Teaching and Learning, called UR.LL.TL was certified by ENoLL, the European Network of Living Labs in 2011 [26]. It nurtures content engineering projects by using a methodology focused on the uses (User-Centered-Design) of these services to match with real expectations of users in a domain. This methodology is based on Sign management on a Creativity or Co-design Platform (CdP).

\section{Experimenting and testing on a Creativity Platform}

At the convergence of Teaching and Learning, there is the CdP (Fig. 7) for experimenting and testing, i.e. Playing (doing) the new products/services. It is an indispensable brick in the methodological plan of treating business and usage processes with a cooking method to acquire its usage value (see below). 


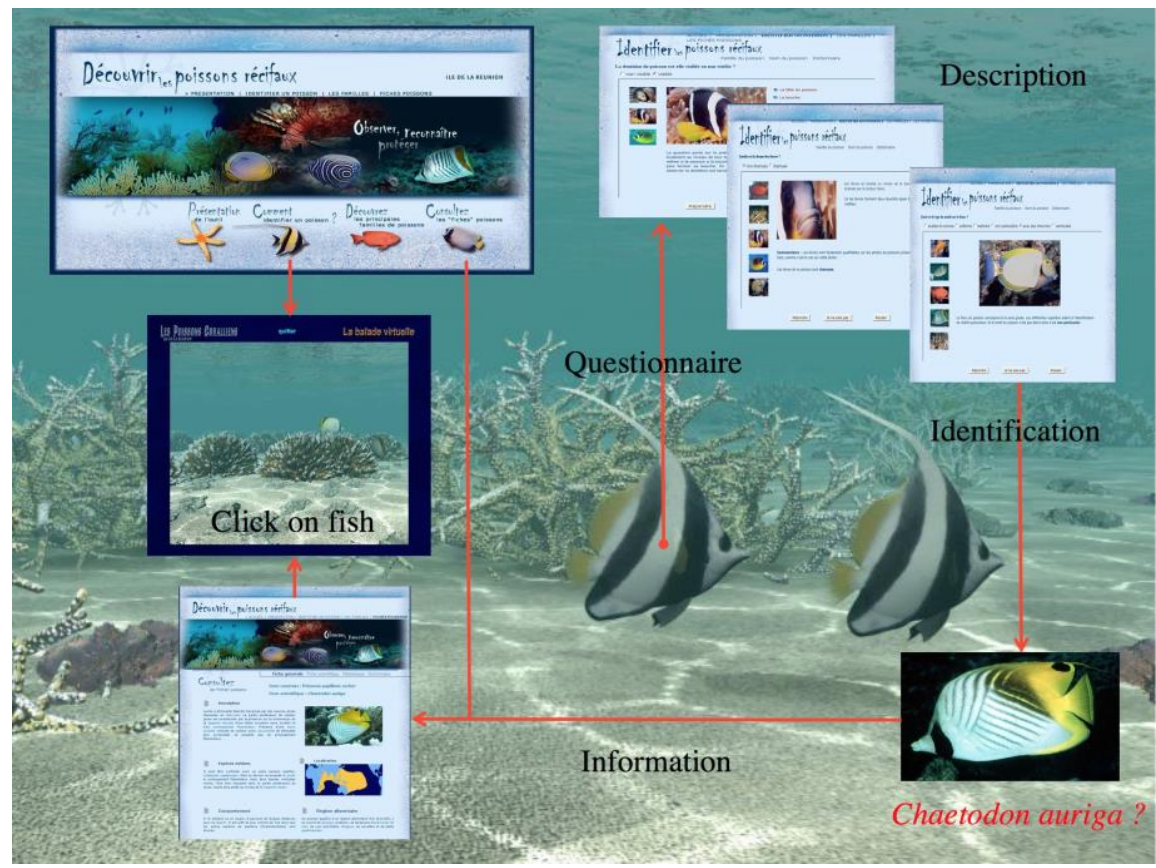

Fig. 5. The usage process of a virtual ballad to identify coral fishes

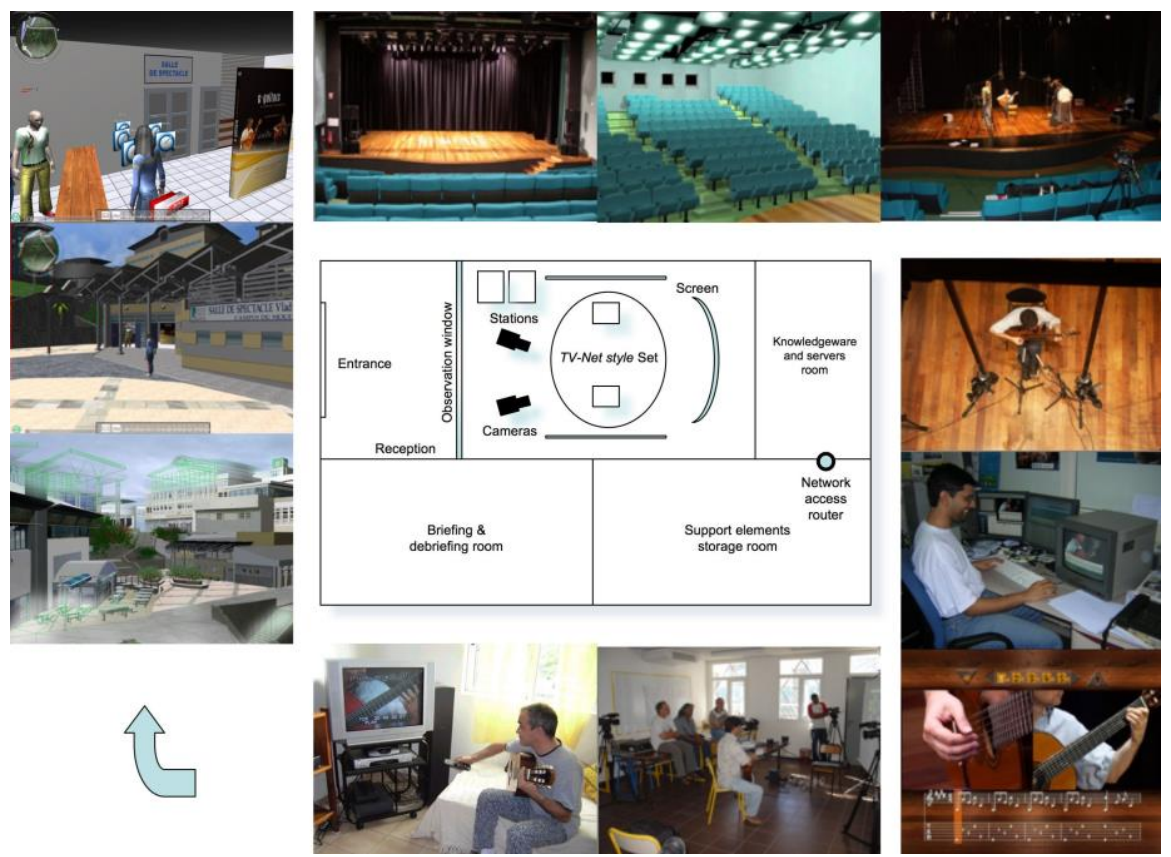

Fig. 6. The production process where reality meets virtual for playing guitar 


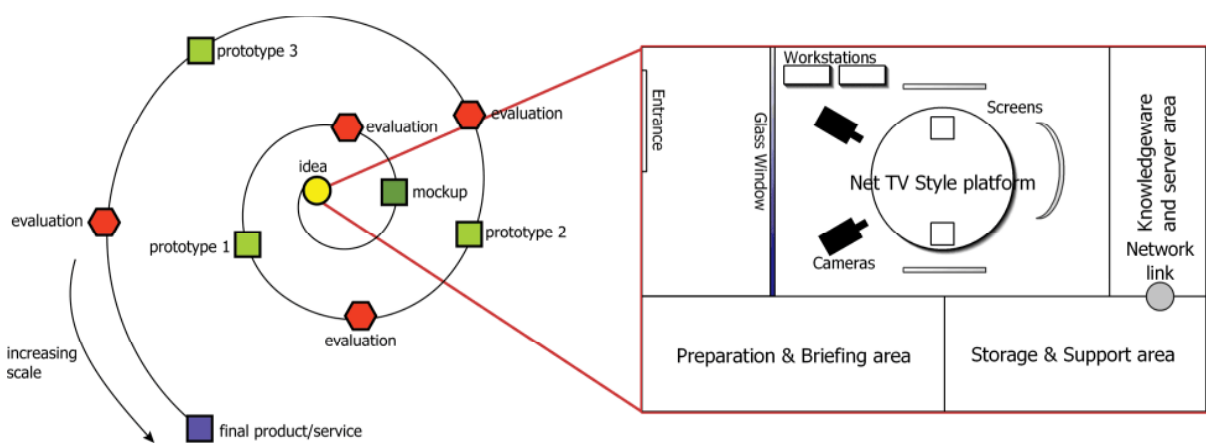

Fig. 7. The Creativity or Co-design Platform to experiment future products/services

The CdP includes a multimedia platform as the one that we find in television studios, but also includes a physical and virtual place to discuss ideas and projects, make models and prototypes, and experiment them in a synchronous (focus group) or asynchronous way (video forum on the Internet).

The potential for exchange and communication is improved by the implementation of spaces devoted to demonstration, as well as the proposition of innovative services: telepresence walls, spontaneous meeting spaces, exchange through virtual reality visits, etc. The meeting space model must be particularly adaptable to varying needs: from video and Web conferencing and interactive distance platform sessions, virtual cafés to interactive television platforms to netTV studios and distant and virtual reality sessions.

The aim of the CdP is to help to design collaboratively mock-ups and prototypes, and experiment them in a physical meeting place. Co-creation in communities of producers (teachers and content managers), editors (computer scientists and graphic designers) and prosumers (proactive consumers) is a significant characteristic of social and open innovation 2.0 that is part of the DNA of Living Labs for bringing trust between all these co-designers. Moreover, a solution cannot be found only with a small team of producers and editors who are the developers. We need also collaborative users (lead-users) as co-designers, and distributors (jurists, communicators and commercials) for marketing the product/service and define its economic value.

In this frame, the CdP instantiates the LL concept by bringing a Playing ground for practicing e-co-innovation [27, 28]. the CdP is the Co-working, Co-learning and Communication Space for researchers and developers, entrepreneurs and users, aimed at defining Collectively the characteristics of e-services to ensure the most direct correspondence between expectations and use. In each case, the objective is to understand the use, achieved by using example platforms, demonstrations, models and simulations, without forgetting questionnaires and structured interviews. The CdP is a way to further understand the conditions of realizing future usages of the services that are analyzed. 


\section{Evaluating the solutions with focus groups and questionnaires}

The next step is to assess the prototypes to formalize a solution that fits user needs.

In an information-based society, it is no longer acceptable to argue in favor of technology alone, ("techno push"), not even if it is backed up by market research ("market driven"): e-services must consider "User Centered Design" [29]. Indeed, innovation in e-services requires an ability to manage not only knowledge of the endusers (through the Knowledge Management design process), but also knowledge supplied by the end-users themselves (through the Customer Knowledge Management usage process) [30].

A first assessment is led early in the process with focus groups on a limited sample of end-users $(<10)$. This qualitative approach provides information on system usage. It is based on filmed scenarios, followed by individual and/or groups interviews of testers. The test will highlight the usability flaws, measure the popularity (or not) of features and discuss those that are missing. For the e-guitar project, the conditions of the experiment are expected to move closer to home use, but the presence of other actors and cameras introduced a bias even though it was acceptable: the volunteers found the approach useful and are generally willing to cooperate. Beyond that, this kind of operation is a strong sign of user involvement in the development because it is an evidence of ownership that is offered.

The second assessment arrives after the first one on a large set of end-users $(>100)$. This semi-quantitative approach is based on questionnaires on paper or on the Web. It should allow to produce statistics on the types of users and their use of the system. But to be relevant, it assumes that we have a large enough sample of returns. For the eguitar project, the IKBS tool was used to determine user profiles and personalize the content delivered to each of them in accordance with his interests and experience.

As a conclusion for assessing the quality of e-services, both approaches are useful and should be undertaken in the evaluation process: focus groups allows to test the tool with end-users to bring qualitative development results, in order that the tool becomes an instrument (see below). Questionnaires and surveys allows to test end-users with the tool/instrument to make statistical analysis, i.e. to bring quantitative results about the qualitative learning of end-users.

At last, for making e-services that count for end-users, their active participation in the process is mandatory for them to adopt the product/service. It is why we emphasize the use of Co-design in our methodology, with a cooking method to pass the product/service from a tool to an instrument and get its usage value.

To resume, the five dimensions of Co-design are:

1. Desiring: being inspired by signs, which are the ingredients of creativity for making ideas become products/services that count for subjects,

2. Observing: being motivated by Living Lab methodologies and processes, based on co-creation, design thinking and user-centered design, 
3. Doing: using a physical and virtual space for running projects, the CdP for persons such as lead-users, end-users, producers, editors, distributors to communicate together and develop collaboratively their ideas, mock-ups, prototypes,

4. Interpreting: using filmed focus groups and illustrated use-cases in questionnaires derived from our Iterative Knowledge Based System (IKBS),

5. Understanding: integrating the result of evaluation of the offer to see if it corresponds to the demand. Is the proposed solution adopted by targeted users? If not, why? Go back to first dimension.

The CdP helps to better understand the transformation of the tool (proposed offer) in an instrument (motivated request) necessary for the creation of the supply of the demand.

\section{The cooking method of Co-design}

One of the goals of Sign management of expert via ICT is to improve the performance of the transfer of their knowledge to non-specialists and to facilitate e-services implementation adapted so that they are used. The $\mathrm{CdP}$ allows business developers and users to specify together the definition of these e-services to facilitate the emergence of their uses. Based on Activity Theory [31], the cooking method of Co-design aims to control the production process of the e-service by the usage process.

To achieve Co-design, we implement iterative methodological processes both on the supply side (production process) and the demand side (usage process). They are based on an experimental approach, combining an inductive generalization step drawing on examples (service conception and elaboration), checking hypotheses (service experimenting) and inferential implementations (range of targeted products). At each stage of the process, between needs and resources, three questions are asked for managing the value of a product/service: 1) what is it good for? 2) what is enough to make it? 3) did we discuss with all stakeholders? These questions on usage value (1), economic value (2) and collaborative value (3), are fundamental to improve the proposed solution iteratively in the Co-design process [32], because it makes sense to reveal the signs of a useful and efficient solution for each stakeholder.

In our Co-design cooking method, usage objects (instrument use, appropriation process and confidence acquisition) of the e-service describe the usage approach of the users on the demand side while business objects (tool engineering, project management and skills acquisiton) describe the production approach of the professionals on the supply side [33] (Fig. 8).

Feedback on the proposed offers with iteration based on the usage objects helps users to express "usage needs" within the CdP. At the start, the proposed offer to be analyzed on the $\mathrm{CdP}$ corresponds to a product/service of which the viability remains to be confirmed by users' tests. The e-service definition will be at its height when its functions translate into a real use. We must move from a shared, intangible vision to a 
concrete and operational product/service, via varied stages of more tangible development (mock-ups and prototypes) to be confirmed.

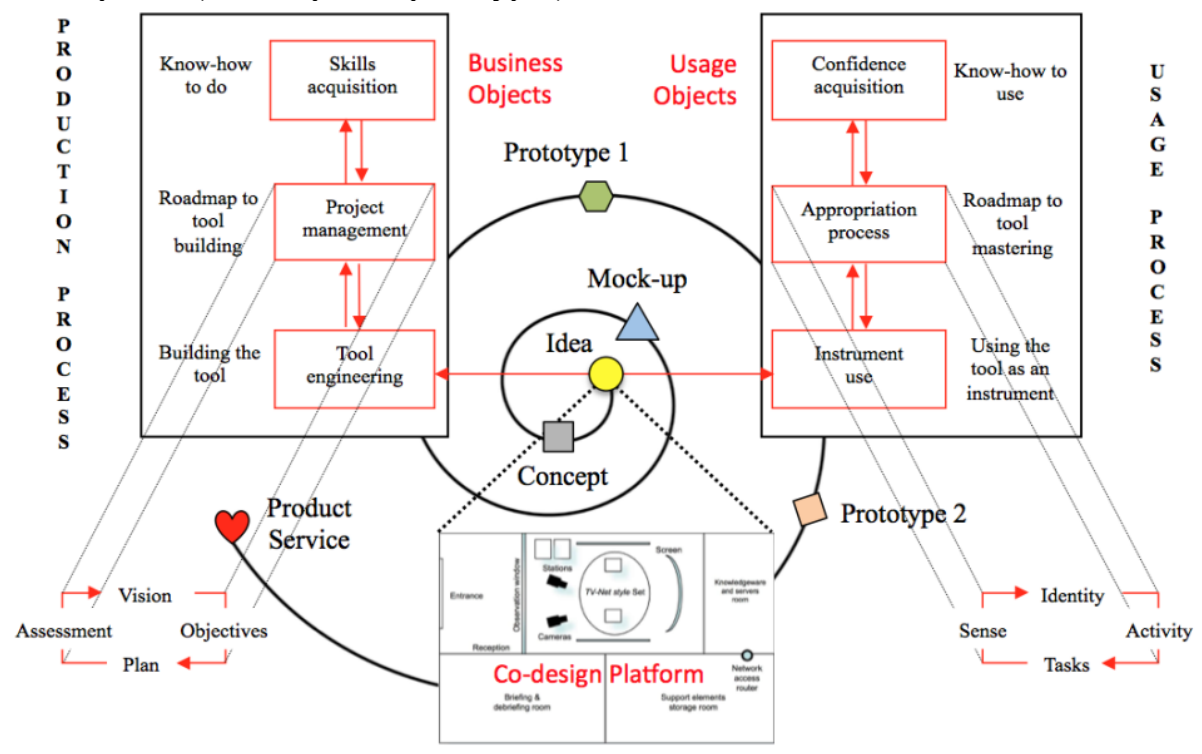

Fig. 8. Interaction between production and usage approaches

The concept of a CdP links the convergence of ICT (production, edition, distribution) with a co-construction methodology (iteration between solutions and uses) within the meeting space of the key actors (researchers, businesses, users). Furthermore, the $\mathrm{CdP}$ is a truly experimental milieu, where all those involved actually contribute to future products/services, responding to users' needs and favoring the highest possible solution's quality.

\section{Production and usage approach analogy}

The facilitating role of the CdP between the world of business supply, and the corresponding world of users demand, manifests itself through the observation of behaviors, uses and the search for specificities that underlie usage. The search for these functions refers to the unconscious mechanism, which "pushes" the end-user to utilize e-services in activities by supplying a meaningful context. The CdP thus aims to classify and identify object uses by describing behavior, practice and specificity.

Conducting an analysis on the CdP requires a proposal of a product/service in its original version (idea, concept), which will be gradually transformed to its final version. The production approach leads to the tool's engineering, which is determined in advance based upon the project management (building process) and the know-how acquisition: 
For the building process of the project management - and all initial engineering - we integrate the four traditional stages (see Fig. 8 on the left):

- The vision of the proposed product/service,

- The definition of objectives,

- The planning of necessary tasks,

- The assessment of results.

These different levels of activity can be described with business objects, which illustrate the professional approach during the development of the product/service. Acquiring skills refers to both the long-term acquisition of knowledge, which also allows development of the know-how and the how-to of a designer's role [34], i.e. the business skills.

Alongside the production approach, on the usage side, the process takes place with the user, based on knowing how to use the e-service in its different forms: user guides, demonstration models, simulations, accompanying lessons, etc., in order to obtain its confidence. Acquiring this knowledge through learning allows the user to describe usage objects, in the same way as an engineer for describing business objects. The appropriation process of the product/service follows 4 stages (see Fig. 8 on the right):

- The desire of identity to the same level as that proposed in the vision of the project building process,

- The activity definition, which is facilitated by the use of the product/service at the same level as stated in the project's objective,

- The following up of tasks in accordance with the project plan,

- Meaningful evaluation of the project's results.

These exchanges lead to debate, contrasting points of view, demonstrations and betatests. Depending on the context, all or some of the meetings may be organized in the form of a tele-visual platform with an animator and producer; exchanges are recorded and lead to a summary and analysis of appropriation processes.

\section{The instrumented Activity Situation model}

The interaction between the designer and the user is closely linked to the transformation of the product/service from a tool to an instrument. Drawing upon the Activity Theory $[4,31,35,36]$, we may define the structure from which the uses will be established. For example, the Instrumented Activity Situation (IAS) model by Rabardel [37] aims to reveal the use of the instrument - a real object of activity that the user expects from the proposed product/service (Fig. 9).

This model defines two different parts within the instrument, the artifact and the use schemes. The artifact is constituted by the invariables of the product/service, with a certain capacity for adaptation, representing the technical and universal aspects, i.e. the tool. Use schemes are structures that have been elaborated by generalizing the invariables linked to action, prolonging the biological organization of the subject and 
having the capacity to assimilate and adapt variables in relation to the subject's outside environment.

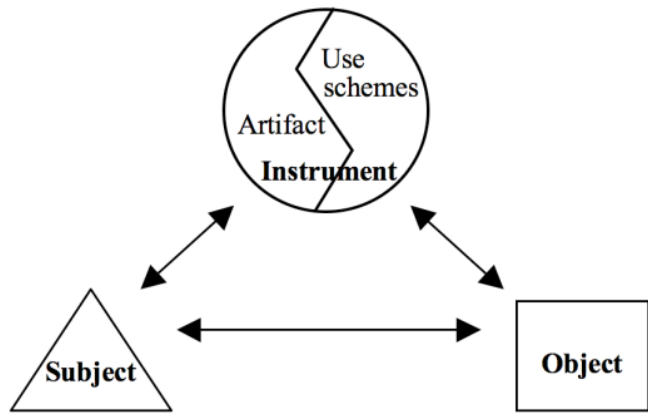

Fig. 9. The IAS model

Each product/service is built by the designer through an initial proposal of an artifact, as well as use schemes, which are intended to ensure the emergence of a specific usage of the service-product. The confrontation between the proposed object and the future users on the $\mathrm{CdP}$ allows a greater understanding of the desired alterations by observing two types of relationships: that of the subject towards the artifact and that of the artifact towards the subject.

The first idea reflects the process of instrumentalization in which the subject gives meaning to the artifact and enriches it. Being based on the intrinsic characteristics of the artifact, the subject, by engaging in the activity, attributes a status and a function to the artifact. This process of attributing a function can be momentary (use) or persistent (usage). In this case, the functions we may refer to as constitutive of the artifact - those that have been imagined by the designer - are incorporated. This is the process of instrumentalization.

The second relationship reflects the process of instrumentation whereby the functions, which make up the artifact, represent constraints on the subject, a framework that structures the activity. They instigate a process of assimilation and adaptation on the subject's part. These two types of processes lead to the incorporation and reorganization of a part of the use schemes, producing a transformed collection that is more adapted to the actual situation.

The instrumental approach using the IAS model applies just as much to the design stage of a new product/service, as to the stage of recursive analysis of existing situations that make use of a product/service already in place (Fig. 10).

The Co-design process thus identifies constituted functions of the product/service being analyzed in order to implement operational modes at the earliest possible stage in the original design.

For Rabardel, the instrument is not only part of the subject's external world, but also the result of individual involvement of the subject in the action of appropriation which varies from the search for identity to accomplishing tasks. Appropriation refers to the process by which the subject reconstructs an artifact's use scheme during a meaningful activity. A tool becomes an instrument when it becomes the vehicle for 
specific actions for the subject: the user establishes the tool as an instrument for $\mathrm{him} /$ herself. The process of this transformation is more important than the result.

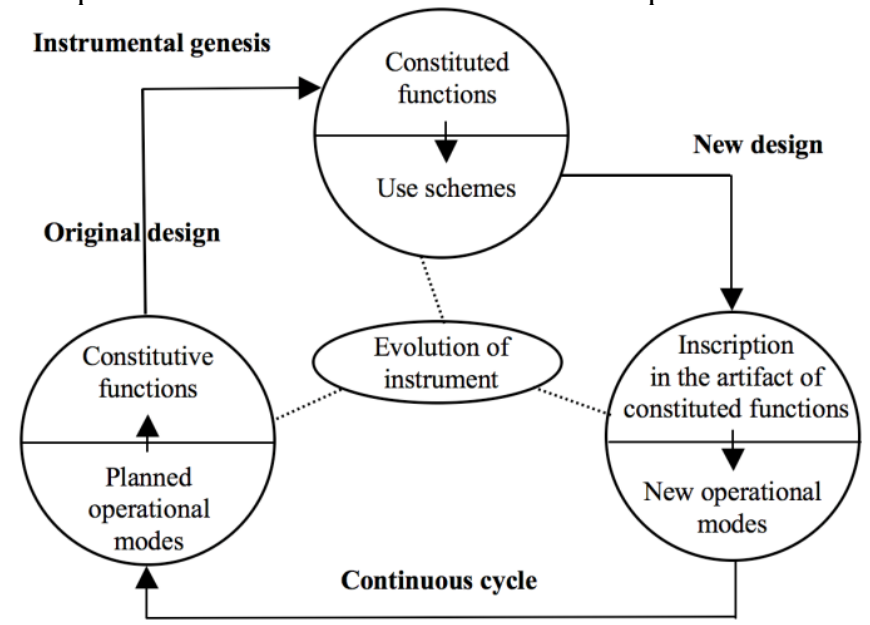

Fig. 10. Stages of transformation: from tool to instrument

The usage of a product/service is significant for a user in that he was able to gradually transform the tool into an instrument. We will now illustrate this cooking method with the design and implementation of an instrumental e-learning service for playing guitar music pieces, the E-guitare project. Note that the E-piano project which followed E-guitare uses the same principles, but we don't illustrate it in this paper. For this instrument, we can notice that the tablet is an artifact that cooresponds to the use scheme of putting a score on a music stand (Fig. 4 below). But the question of using fingers for triggering actions on this support is an IHM concern that needs ergonomic studies for evaluating the adaptation of the musician to this artifact.

\section{$6 \quad$ E-guitar example}

This project, initiated in 2003, aims to create intuitive learning systems to help people play guitar pieces through multimedia means. This research project lasted four years until the solicitation of the incubator for the creation of a start-up. E-guitare was the support of a computer science $\mathrm{PhD}$ [38]. It was conducted in partnership with the Region's National Conservatory (CNR) [39] and two teachers, Patrick Sida and David Hoarau, who supplied the pieces in classical guitar with their pedagogy. The starting point is the presentation of a course with a teacher. We sought to reproduce the flow of information involved in their lessons, adding the interactive dimension. Compared to the technological context of the time, it appeared that the DVD medium was the most suitable, both in terms of capacity, standardization, or cost of access. 


\section{Business and usage objects instantiation}

The vision in the building process is to "bring the teacher at home" to play classical guitar pieces. It results in the following objectives:

The system should provide multi-angle viewing of the teacher who plays the piece. At any time, the learner can switch from one view to another in real time and in full screen, the principle being to learn by imitation, looking at the model and replicating the gestures. Another fundamental feature should be added to facilitate this process: a pre-calculated and contextual slow-motion mode allowing to halve the execution speed while maintaining an excellent audiovisual quality. Then, stepping into the piece is done segment by segment relative to a reference that is the score or the musical structure (intro, verse, chorus, ...). Learning occurring through repetition, a double loop system (pre-set by the designers or customized by the user) must be implemented.

The question of identity in the appropriation process arises from the start of the project: indeed, as the place of the user is central in the development, he must be involved in the construction of e-services (co-design). It turns out that the team members are themselves guitarists and early adopters. This feature is fundamental to the adequacy of the proposed vision and the problem to solve. The origin of the project is also the finding of a gap: even if the learners follow a course with a teacher, it is difficult for them to get help to solve technical problems in deciphering between courses, when left to one's own, resulting in a waste of time.

The activities for solving a music piece are conducted in the order shown in Fig. 11.

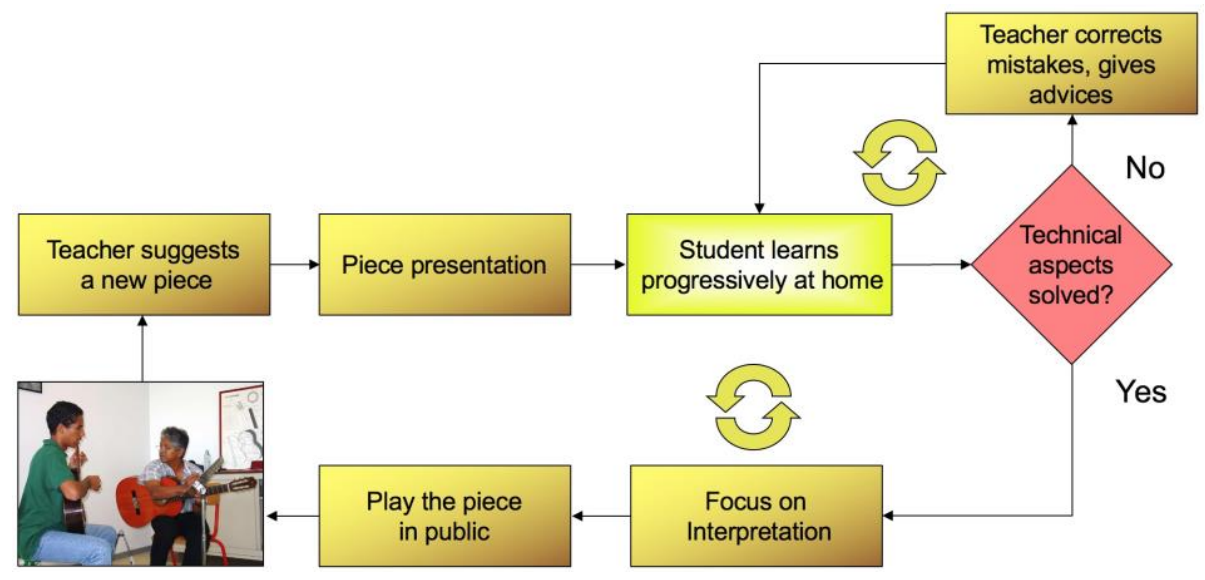

Fig. 11. The different activities for learning a piece of guitar

We realize that the technical difficulties involved most of the student work time. The E-guitare project aims to the acquisition and transmission of knowledge of conservatory teachers and music schools (gestures, fingering of the right hand and left hand techniques and tips for delicate passages, etc.) on pieces they interpret. The project responds to a need for students and guitar enthusiasts to understand how to execute the 
parts of a repertoire of Spanish guitar, Brazilian, etc. in an academic and professional manner. There is a large unmet demand for guitar lessons and "good practices" for enthusiasts who are not teachers to support them in their learning. The conservatory is the place that guarantees quality of education to progress in learning the right techniques, i.e. the independence of the fingers of the right hand, etc.

Tool development tasks have focused on technical assistance for the student to correctly solve the difficult passages of the piece (karaoke, slow motion, looping, advice, etc.). They are then strung together naturally by dividing the sub-tasks within the project team composed of graphic designers and computer scientists.

The peculiarity of the designer/user has had a very positive impact on the rate of progression of tasks to be solved with a plan, because the first feedbacks have been very fast. The iterative development process could be very quick at the beginning and transparently (orally) with this internal evaluation. Subsequently, we logically opened the tool to new testers to conduct a more systematic external evaluation. Students of classical guitar class of CNR were naturally involved (teachers are our experts), but also independent people who represent our second type of public.

The evaluation was based on two constructs: the semi-quantitative approach, on the one hand, was based on questionnaires (either on paper or online). This allowed us to produce statistics relating to the types of users and their use of the system. For it to be significant, it necessitated the return of a large sample of questionnaires. The use of the IKBS tool [40], allowed us to determine user profiles (Fig. 12). It is therefore possible to personalize the content to be delivered to each user in accordance with their interest and experience. The qualitative approach, on the other hand, produced information regarding system usage. It was based on actual situations and filmed focus groups on the CdP (see Fig. 6) and was followed up with interviews of individuals and/or testing groups. The test highlighted faults in ergonomics, evaluated the popularity of the applications and discussed deficiencies. The conditions of the experiment were supposed to resemble home use, but the presence of others as well as cameras clearly represented a bias, but one that was accepted in the end.

The sense of appreciation was much more apparent in focus groups, as opposed to the reaction to the questionnaire which was rather tedious. Volunteers found the process useful and were generally willing to cooperate. Beyond the above considerations, this type of operation was a strong sign of the users' implication in the development as it bears witness to the appropriation process proposed to them.

A communication infrastructure was then set up as a community Website, to organize exchanges between the various stakeholders: development team (researchers, engineers, graphic designers, video professionals, webmaster) guitar teachers, students and external consultants. The CdP gathering all these stakeholders first took the form of the Canter theater that served as a place of guitar pieces' registration, and offered the frame of reference for our Website [41]. Later, it also took the form of a work room putting testers in situation, and a virtual meeting of avatars in the e-campus project (Fig. $6)$. 


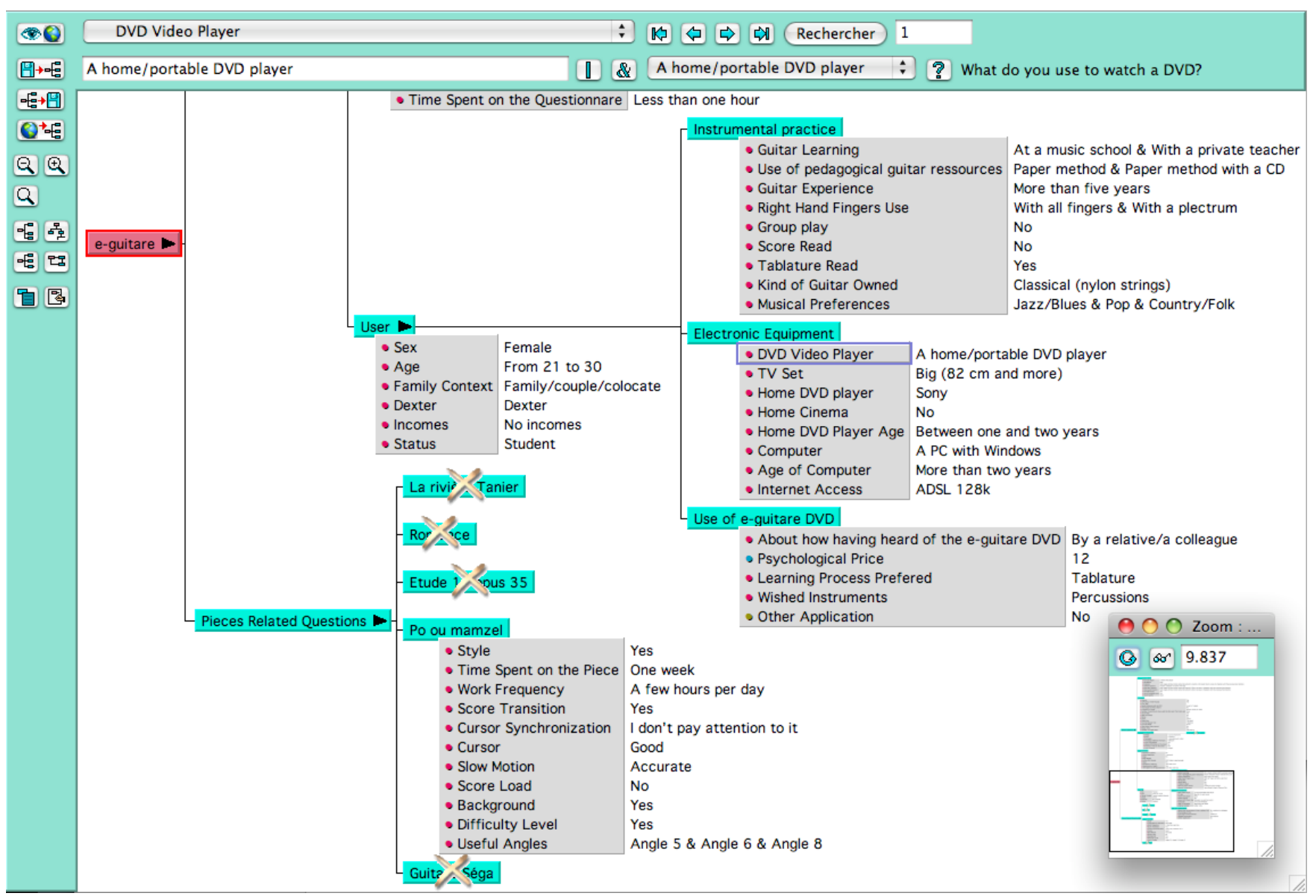

Fig. 12. Use of IKBS for evaluating E-guitare customer profiles 


\section{E-guitar IAS instantiation}

To illustrate the passage of the tool to the instrument with the IAS model, we take the example of conversion of the tool over time (CD-ROM, DVD-TV, DVD-ROM, FIGS) for some justified reasons related to its use. First, here is the cycle of evolution of the e-service until 2009 (Fig. 13).

Reflection on the E-guitar project began in 2002 with the design of a simulated model in QuickTime video that was later improved in 2003 (screens 1 and 2 in Fig. 13) and summarily implanted to make it interactive (CD -ROM).

This work was the basis of a request for financing E-guitar at the end of that year under the FEDER DOCUP 2000-2006 ICT funds. After acceptance of the application, the first DVD prototype was designed in 2004. The project leader has been trained in production tools (Final Cut Pro and DVD Studio Pro, Fig. 6 on the right) which enabled him to improve the interface thanks to feedback from designers/users (internal evaluation) for one year (screen 3 of Fig. 13).

The year 2005 was the beginning of the first public iteration (external evaluation). The first prototype implanted all the features (karaoke, time stretching, looping) and received a near trade dress. It was pressed at 500 copies. The test campaign that followed was spread over six months, to allow sufficient time for users to practice the DVD.

The semi-quantitative approach with the external questionnaire made with IKBS has not had the desired impact because of lower return rate than expected (one questionnaire on four was returned). After a quick survey of a selection of people, it appeared that the main causes of demotivation were the length of the questionnaire (up to 130 questions based on the experience of the tester, see Fig. 12) and its unpleasing and impersonal aspect. And yet, the DVD was a gift in return of the questionnaire!

On the contrary, the qualitative approach was used to check that the features we developed were helpful, except for a hypothesis that could not be maintained: the choice to develop a DVD only on TV with the navigation remote control (Fig. 6 below). Indeed, the users work with this DVD to learn the pieces, and this usage value needs concentration. Television is a way for a family gathering around a movie in the living room and not a way to work its instrument, which is better done in a bedroom.

The proposed artifact with DVD-TV is not in line with the use scheme, so it had to evolve to go to the DVD-ROM media that can be run on a computer. This has had consequences on the ergonomics of the e-service which had to be reworked seriously in the prototype number 2 (clickable objects). In 2005, an economic and legal study was also conducted to find out the DVD market situation in France and the USA, actors and trends in costs (evaluation of the exchange value), intellectual property rights applicable, the types of contracts to be negotiated in the marketing phase [42].

Our DVD was then compared to a commercial product presented as similar. The testers were unanimous in confirming that our e-learning experience was far better than the commercial solution [38]. Points to review were at the level of ergonomics to simplify access based on the media (television or computer) and the lack of pedagogical speech from the teacher. Similarly, the public wanted greater diversity of styles and even other instruments. 


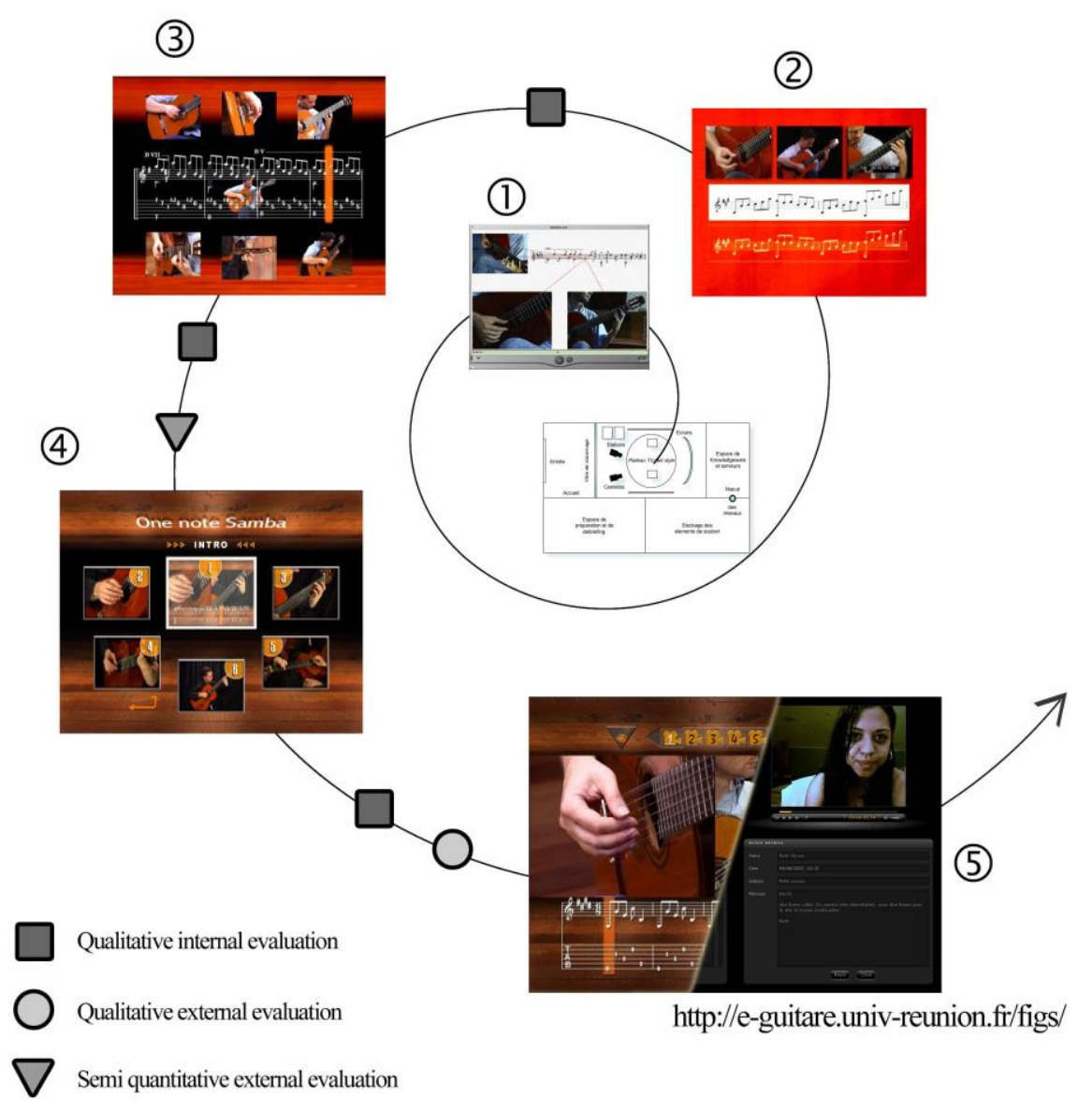

Fig. 13. Evolution cycle of E-guitar solutions through evaluations

These returns have therefore possible to draw up the results of the second public iteration of the development of the e-service. A new version was developed in 2006 (Screen 4 in Fig. 13), incorporating a dual control interface, with the remote control or with the mouse for a better return on your selection. Oral explanations sequences, called teaching tips were added contextually to the most complex passages, to offer problemsolving strategies. This version was distributed and evaluated on a large scale quantitatively, after a period of adjustments carried out internally by the designers/users. The project of incubation of a start-up for DVD production in instrumental e-learning was launched in early 2007 [43].

Typically, users are fond of communication, both from students to teachers or between learners themselves. The DVD is a medium suitable for transmission of knowledge from teachers to students. But when pressed or engraved, it is not possible to update it easily. Hence the idea of coupling it to an online service, which would restore a two-way dialogue between teachers and learners (screen 5 in Fig. 13). We 
developed a web application called FIGS (Flash Interactive Guitar Saloon, Fig. 4) playing the role of an audio-video forum suited to musical learning: the conceptual specificity comes from the ability to locate each contribution to a passage of the piece [44].

This period marks a transformation of the E-guitar tool on DVD (offline) to the Eguitar Web tool (Online). The community site is the living part of the project: it gives a support for DVD video, as an interactive service feedback when learning is made at home. With FIGS, we initialize a true collective work in music Teaching and Learning by Playing. Indeed, the Teaching mode is when the professor is distributing his interpretation of a piece on DVD. The Learning mode is when a student is working this piece at home with the quality of video and sound on DVD, and is asking questions to the professor by filming himself with his webcam. Note that video recordings of professors from different angles that were recorded in the DVD are also available in smaller format in FIGS. To ask a question about a passage, learners perform a marking (beginning - end) on the time slider and record video at home with their camera on the passages they want to show to the teacher. The community Web site will have to include a new usage value with the system of video glosses dedicated to learning musical pieces, as currently shown by services 2.0 of YouTube or Daily Motion for video.

The evaluation of the third public iteration therefore concerned an overall system consisting of two solutions, offline (DVD) and online (FIGS). The feedback was very positive because FIGS complements the DVD and enriches itself with discussions. It provides an accessible information service on guitar pieces based on natural media for the practice of the instrument. This new situation has not stopped investigations into each solution taken separately. The DVD video is thus the core of the e-service for Teaching and Learning pieces of music. The video glosses system complements the device to allow the exchange of techniques and interpretations of difficult passages. We thus move from an expert vision centered on the transmission of knowledge to a community vision centered on shared signs.

As shown in Fig. 4, the iterative process of development of an e-learning solution went on between 2009 and 2013 with another $\mathrm{PhD}$ in computer science based on playing the piano [45]. @-MUSE introduced the possibility for teachers and learners to annotate musical scores on tablets with personal videos explanations, for getting technical interpretations of signs thanks to the MusicXML representation format.

\section{Conclusion}

At the beginning of this work on Sign management, there was the term of gloss for discussing instrumental techniques, as we wanted to implement a video interpretations management system for FIGS with our teachers. That device revealed a new form of possible dialogue between learners and teachers in the field of music.

Sign management is the new ecosystem of Knowledge management that we want to promote on our $\mathrm{CdP}$. All areas of e-learning requiring visualization of know-how (gestures, hand, tips and tricks, glances) are concerned. Besides music, this can touch the culinary arts, dance, visual arts, crafts, observation guides, etc. In our case, the 
music domain was privileged because we are also musicians. As we know our limits in learning a musical instrument, we would like to benefit from such a service for ourselves. Experts are content producers that show their performance and explain their fingerings and gestures. We are computer scientists and editors who want to offer an ergonomic e-learning service to play efficiently musical pieces.

So we have to switch from the domain of Knowledge management focused on experts' representation of objects to the domain of Sign management dedicated also on the signification of objects from different subjects. Signification is the key psychological and constructivist process that makes sense for finding a consensus between people by sharing data, information and knowledge, i.e. Signs. And that's why the concept of Sign is more relevant than the one of Knowledge for biodiversity and music enhancement, because it includes the interpreter in the process of description of objects. To find shared usage values, we need to deal with living knowledge for making e-services with people and not only with specialists.

Sign management is also a bi-directional dialogue between teachers and learners. It stresses the interest of sharing subjects' interpretations by edutainment, i.e. Teaching and Learning by Playing with subjective know-how (glosses) of end-users, on top of transmission of fossilized objects, i.e. explicit knowledge of experts found in documents or books. This new framework tries to give sense to collaboration between all stakeholders (specialists, end-users, lead users) acting in their communities. When playing together, they can show their interpretations, explain why some are better than others, and find a consensus for being more objective, i.e. by confronting subjectivities ("show me how you do it!").

Sign management emphasizes the signification of objects by different subjects, i.e. the inscription of objects by subjects or the description of signed objects (sobjects?). It would allow each user to show their interpretations of objects with multimedia content (audio, video) annotated in textual descriptions.

The interest of Sign management is: 1) to share know-how between practitioners of a community who can play together 2) to emphasize the engineering and use of data, information and knowledge from the viewpoint of a subject 3) this personalized approach is more user-centered-design.

Thus, our next step will be to develop a Sign Base Management System with its ISBS platform (Iterative Sign Base System) to share Signs (interpretations) on the Web in a collaborative way. The principle would be to increase IKBS semantic functionalities (ontologies, descriptions, classifications, identifications) with groupware, multimedia content annotation and geo localized immersion, so that both experts and amateurs can describe their interpretations in the form of inscriptions in signs bases.

These audio-visual inscriptions are the objects of human interpretation we seek to extract and manage because they coincide with a real demand [46]. The Co-design methodology that we propose for Sign management is based on the identification, extraction and conversion of these multimedia objects to know how to make things in signs bases and not only to know what are these things in knowledge bases. ISBS will be built as a new virtual platform in our Teaching and Learning by Playing Living Lab and tested on a Creativity Platform to handle activities in both artistic and scientific 
areas. It aims to produce innovative e-co-education services for managing signs collaboratively.

\section{References}

1. Saussure de, F.: Nature of the Linguistics Sign, In: Bally, C., Sechehaye, A. (eds.), Cours de Linguistique Générale, McGraw Hill Education (1916)

2. Peirce, C.S.: Elements of Logic, In: Hartshone, C. H., Weiss, P. (eds.) Collected Papers of C.S. Peirce (1839-1914). The Belknap Press, Harvard Univ. Press, Cambridge, MA (1965)

3. von Uexküll, J.: Theoretical Biology. pp. xvi+362. Kegan Paul, Trench, Trubner \& Co., London (1926) (Transl. by D. L. MacKinnon. International Library of Psychology, Philosophy and Scientific Method)

4. Vygotsky., L.: Mind in society: the development of higher mental processes, Cambridge, MA: Harvard University Press, (1978)

5. Barbieri, M.: Introduction to Biosemiotics. The new biological synthesis. Springer (2007)

6. Conruyt, N., Sébastien, V., Sebastien, O., Grosser, D., Sébastien, D.: From Knowledge transmission to Sign sharing: Semiotic Web as a new paradigm for Teaching and Learning in the Future Internet, Artificial Intelligence for Knowledge Management, E. MercierLaurent and D. Boulanger (Eds.): AI4KM 2012, IFIP AICT 422, pp. 170-188, Springer, (2014)

7. Conruyt, N., Sébastien, V., Sebastien, O., Sébastien, D., Grosser, D.: Sign management for the future of e-education: examples of collaborative e-services in a Living Lab, Artificial Intelligence for Knowledge Management, E. Mercier-Laurent et al (Eds.): AI4KM 2014, IFIP AICT 469, pp. 1-20, Springer, (2015)

8. Blancard, D, Bonnet, A., Coleno, A.: SNL $+\mathrm{t}$ mrxrsdme expert en maladies des tomates, PHM Revue horticole (261), pp. 7-14 (1985)

9. Manago, M., Conruyt, N.: Using information technology to solve real world problems. In: Contemporary Knowledge Engineering and Cognition, Lecture notes in Computer Science, 622, F. Schmalhoffer, G. Strube et T. Wetter (Eds.), Springer-Verlag, pp. 22-37 (1992)

10. Manago, M., Althoff, K.D., Auriol, E., Sq ogniner, R., Wess, S., Conruyt, N., Maurer, F.: Induction and reasoning from cases. In Proceedings of the First European Workshop on Case-Based Reasoning, M.M. Richter, S. Wess, K.D. Althoff et F. Maurer (Eds.), SpringerVerlag, pp. 313-318 (1993)

11. Le Renard, J., Conruyt, N.: On the representation of observational data used for classification and identification of natural objects. In: New Approaches in Classification and Data Analysis, Studies in Classification, Data Analysis, and Knowledge Organization, pp. 308-315, Springer (1994)

12. Conruyt, N., Grosser, D.: Knowledge engineering in environmental sciences with IKBS, AI Communications, The European Journal on Artificial Intelligence, 16(4): pp. 267-278, IOS Press, (2003)

13. Conruyt, N, Grosser, D., Geynet, Y., Faure, G., Pichon, M., Guillaume, M., Gravier-Bonnet. N.: IKBS, a knowledge base management system for reengineering Systematics: application to corals of the Mascarene Archipelago, In Proceedings of the 9th Int. Coral Reef Symposium, 2:909-916, Bali, (2000)

14. Rd́bastien, O., Conruyt, N., Conruyt. P.: E-guitare, an instrumental e-learning project, Proc. of the 4th Open Workshop of MusicNetwork: Integration of Music in Multimedia Applications, WEDELMUSIC'2004, pp. 14-16, September 2004, Barcelona, Spain, (2004) 
15. Rd́bastien, U-+Rd́bastien, D., Conruyt, N.: Constituting a Musical Sign Base through Score Analysis and Annotation, International Journal On Advances in Networks and Services, 4(3\&4):386-398, IARIA, (2011)

16. http://musescore.org/en

17. http://robert.bvdep.com/public/vep/Pages_HTML/DISEGNO.HTM

18. Curley, M., Salmelin, B.: Open Innovation 2.0: A New Paradigm, OISPG, (2013)

19. Pallot, M., Krawczyk, P., Kivilehto, A.: User-Centred Open Innovation Domain Landscape within the European Network of Living Labs, Proceedings of the ISPIM 2013 Conference, Helsinki, Finland, June (2013)

20. Ballon, P., Schuurman, D.: Living Labs: Concept, Tools and Cases. info, 17(4), (2015)

21. http://www.slideshare.net/conruyt/urlltl www.slideshare.net/conruyt/living-lab-and-digital-culturalheritage

22. New Media Consortium (2013), http://www.nmc.org/publications

23. http://vieoceane.free.fr/poissons/menu.html

24. http://immersion. univ-reunion. fr/wordpress/

25. Sebastien, D., Sebastien, O., Conruyt, N.: e-campus: a MMORPG providing e-Services to campus users, in Int. Journal of Intelligent Games \& Simulation, IJIGS, (2008)

26. http://www. openlivinglabs .eu/livinglab/university-reunionisland-living-lab-teaching-and-learning

27. Mercier-Laurent, E.: Innovation Ecosystems, Wiley-ISTE, (2011)

28. Conruyt, N.: E-co-innovation for making e-services: Living Labs as a human-centered digital ecosystem for education with ICT, 7th IEEE International Conference on Digital Ecosystems and Technologies, DEST 2013, July 24-26, Menlo Park, California, USA, (2013)

29. Bevan, N.: Quality in use: meeting user needs for quality, Journal of Systems and Software, 49(1), pp. 89-96, (1999)

30. Gibbert, M., Leibold M., Probst, G.: Five styles of Customer Knowledge Management, and how smart companies put them into action, European Management Journal Vol. 20, No. 5, pp. 459-469, (2002)

31. Nardi, B.A.: Context and Consciousness: Activity Theory and Human-Computer Interaction, Cambridge, MA: MIT Press, (1996)

32. http://valeursetmanagement.com/

33. @ancqn+S-+Bg`t uds+I-L -9Naidsr 1 d́tier. Editions Eyrolles, 231 p., (1998)

34. Odqqdmt c +O-9Bnmrsq hod cdr bnl od́sdmbdr cd̀r kécole, Paris: ESF, (1997)

35. Engeström, Y.: Learning by expanding: an activity-theoretical approach to developmental research, Orienta-Konsultit Oy, Helsinki (1987)

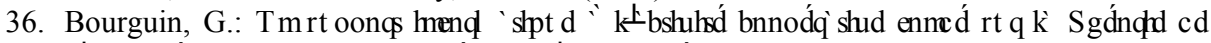
kÆabshubd 9kd oqnids C@QD+Sgdrd cd kł mhudqrisd de Lille 1, 217 p., (2000)

37. Rabardel, P.: Les Hommes et les Technologies, approche cognitive des instruments contemporains, Ed. Armand Colin, 240 p., (1995)

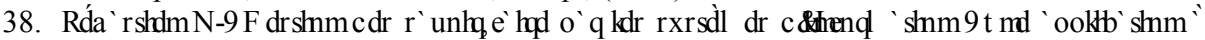
k\&ooqdmstrr` f d hmrsq 1 dms' k+Sgd̀d cd cnbsnq’ s+T mhudqhsd́ cd K' Qd́union, (2009)

39. http://conservatoire.regionreunion.com

40. http://ikbs.sourceforge.net/

41. http://e-guitare.univ-reunion.fr/

42. J h̀+@-9Dst cd d́conomique et juridique pour le projet E-guitare, KLF, New York (2005) 


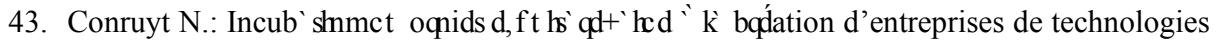
innovantes+Hbt a `sdt qqúf hmm kcd K` Qd́t ninm+T nhudqrbd́ cd K` Qd́union, (2007)

44. Rd́bastien O., Conruyt N., Calderoni S.: Enhancing Music Learning Experience through a Dedicated Web 2.0 Oriented Service, Proceedings of I-media'2007 and I-semantics'2007, J.UCS, 5-7 Sept., Graz, Austria, (2007)

45. Rd́a `rshdmU-9Cd k F drshmcdr Bnmmi hrr nbdr “'k F drshmedr Rlf modr 9@oolłb shm ” la Transmission des Savoir-faire Musicaux, Tgd̀se de doctorat, Univ cd K Qd́union, (2013)

46. Pachet, F.: Les nouveaux enjeux de la reification, L'Objet, 10(4), (2004) 